\title{
Pelatihan Pembuatan Eco-Friendly Detergen Daun Balik Angin (Alphitonia Excelsa) pada Kelompok Ibu-ibu di Desa Mandi Angin
}

\section{Training on Preparation of Eco-Friendly Detergent Leaves Balik Angin (Alphitonia Excelsa) for Mothers Group in Mandi Angin Village}

\author{
Muhammad Faisal Machdie, Kurdiansyah*, Gusti Abdul R. Thamrin \\ Program Studi Teknologi Hasil Hutan, Fakultas Kehutanan, Universitas Lambung Mangkurat, \\ Jalan Ahmad Yani Km. 35, Banjarbaru, Kalimantan Selatan 70714. \\ *Penulis Korespondensi: E-mail: ir.kurdiansyah@gmail.com \\ Diterima Oktober 2020/Disetujui Oktober 2021
}

\begin{abstract}
ABSTRAK
Kawasan Hutan dengan Tujuan Khusus (KHDTK) Universitas Lambung Mangkurat merupakan kawasan hutan dengan berbagai jenis tumbuhan dan pepohonan. KHDTK berada dekat dengan wilayah pemukiman warga. Adanya aktivitas warga di sekitar KHDTK secara tidak langsung akan memberikan dampak keberlangsungan KHDTK. Salah satu aktivitas warga yang memberikan dampak bagi KHDTK adalah kegiatan mandi, cuci, dan kakus (MCK). Kegiatan pengabdian masyarakat ini bertujuan memberikan wawasan terhadap dampak penggunaan detergen kimia terhadap kesehatan dan lingkungan serta meningkatkan pemberdayaan masyarakat di sekitar kawasan KHDTK dalam mengolah sumber daya alam berupa daun balik angin menjadi detergen ramah lingkungan. Metode pelaksanaan terdiri dari dua tahap, yaitu tahap penyuluhan dan tahap pembuatan detergen ramah lingkungan. Penyuluhan dilakukan dengan memberikan pengetahuan tentang dampak detergen sintetis dan pembuatan detergen ramah lingkungan. Pada kegiatan ini bahan dasar yang digunakan adalah tumbuhan balik angin karena daun ini memiliki kandungan saponin. Daun balik angin di ekstraksi dengan metode infusa. Hasil evaluasi terhadap kegiatan yang dilakukan menunjukkan adanya peningkatan pengetahuan masyarakat terhadap dampak detergen sintetis bagi lingkunngan dan peningkatan keterampilan masyarakat dalam membuat detergen ramah lingkungan. Kegiatan ini sangat bermanfaat dalam meningkatkan pengetahuan dan keterampilan masyarakat.
\end{abstract}

Kata kunci: dampak, daun balik angin, detergen, KHDTK, ramah lingkungan

\begin{abstract}
Special Purpose Forest Area (KHDTK) Lambung Mangkurat University is a forest area with types of plants and trees. KHDTK is close to residential areas. The existence of community activities around KHDTK will indirectly have an impact on the sustainability of KHDTK. The community activities that impact KHDTK are bathing, washing, and latrine activities (MCK). This community activity provides insight into the impact of using chemical detergents on health and the environment, as well as increasing community empowerment around the KHDTK area in processing natural resources in the form of processing leaves into environmentally friendly detergents. The implementation method consists of two steps, the first step is counseling, and the second step is the preparation of eco-friendly detergents. Counseling carried out by providing knowledge about the impact of synthetic detergents and the manufacture of environmentally friendly detergents. In this activity, the active ingredients used are balik angin leaves because these leaves contain saponins. Leaves balik angin extraction using the infusion method. The results of the evaluation of the activities showed an increase in public knowledge about the impact of synthetic detergents on the environment and an increase in community skills in making environmentally friendly detergents. This activity is very useful in increasing the knowledge and skills of the community.
\end{abstract}

Keywords: balik angina leaves, detergents, eco-friendly, impact, KHDTK

\section{PENDAHULUAN}

Air limbah rumah tangga merupakan sumber yang banyak ditemukan di lingkungan. Bahan utama yang terdapat pada detergen adalah surfaktan. Surfaktan merupakan salah satu senyawa yang memiliki fungsi untuk menurunkan tegangan permukaan pada permukaan air, sehingga akan memudahkan untuk membasahi dan menghilangkan noda pada kain. Alkyl benzene sulphonate (ABS) merupakan 
surfaktan yang terdapat pada detergen yang tergolong keras. Detergen sukar diurai oleh mikroorganisme (nonbiodegradable), sehingga dapat menimbulkan pencemaran lingkungan dan berbahaya bagi kesehatan karena dapat menyebabkan gangguan pada kulit dan pernafasan. Surfaktan lain yang digunakan untuk menggantikan ABS adalah Linear Alkylbenzene Sulfonate (LAS). LAS juga merupakan surfaktan yang berpotensi mencemari lingkungan. Peningkatan penggunaan detergen oleh masyarakat telah secara nyata menghasilkan limbah cair domestik yang mengandung LAS dan mencemari ekosistem sungai (Hendra et al. 2016). Konsentrasi LAS di ekosistem sungai di kota-kota besar yang padat penduduknya khususnya di Indonesia sudah melampaui nilai ambang 0,5 mg/L (Haderiah \& Dewi 2016).

Wilayah Kampung Baru Mandi Angin merupakan desa yang terletak dekat Kawasan Hutan dengan Tujuan Khusus (KHDTK) Universitas Lambung Mangkurat. KHDTK merupakan kawasan hutan yang banyak ditumbuhi oleh berbagai jenis tanaman dan pepohonan. Adanya pemukiman warga di dekat KHDTK tidak lepas dari kegiatan MCK yang menggunakan detergen. Limbah detergen yang dihasilkan mengakibatkan berkurangnya tingkat kesuburan tanah pada KHDTK dan memengaruhi pertumbuhan tanaman dan pepohonan di KHDTK.

Penggunaan detergen ramah lingkungan menjadi solusi untuk mengurangi penggunaan detergen konvensional. Pemanfaatan bahan alam sebagai pengganti surfaktan dapat dijadikan alternatif lain dalam penggunaan detergen ramah lingkungan. Salah satu tumbuhan yang dapat dimanfaatkan sebagai detergen ramah lingkungan adalah tumbuhan balik angin (Alphitonia excelsa). Tumbuhan balik angin merupakan pohon dengan tinggi $17 \mathrm{~m}$ yang banyak tumbuh di daerah KHDTK Mandi Angin. Daun balik angin memiliki kandungan saponin (Rachmawati 2019). Saponin adalah senyawa bahan alam penghasil busa yang dapat dimanfaatkan pada industri detergen, sabun dan shampoo (Supandi \& Setwiawan 2019). Saponin pada daun balik angin menghasilkan busa yang berfungsi sebagai bahan pencuci atau detergen dan bertindak sebagai bahan aktif atau surfaktan dari pembuatan detergen ramah lingkungan. Saponin adalah salah satu surfaktan berbasis hayati yang paling terkenal dan berfungsi seperti sabun alami. Belakangan ini, tanaman yang mengandung saponin semakin diminati karena sifat fungsionalnya yang sangat baik dan manfaat kesehatannya. Selain itu, penggunaan saponin sebagai bahan pembersih aman bagi lingkungan, dapat terurai secara hayati, terbarukan, serta dapat beradaptasi secara ekologis (Wisetkomolmat et al. 2019).

Kegiatan pengabdian dilakukan dengan dua tahap, yaitu tahap penyuluhan dan tahap praktik pembuatan. Kegiatan penyuluhan pengabdian dilaksanakan untuk memberikan pengetahuan pada peserta mengenai dampak penggunaan detergen kimia yang diukur berdasarkan kuesioner yang telah diberikan. Tahapan selanjutnya adalah praktik pembuatan detergen menggunakan daun balik angin sebagai upaya untuk meminimalisir penggunaan detergen konvensional dengan penggunaan detergen alternatif yang ramah lingkungan dari daun balik angin sehingga ekosistem di KHDTK dapat terjaga.

Kegiatan pengabdian masyarakat ini bertujuan memberikan wawasan terhadap dampak penggunaan detergen kimia terhadap kesehatan dan lingkungan serta meningkatkan pemberdayaan masyarakat di sekitar kawasan KHDTK dalam mengolah sumber daya alam berupa daun balik angin menjadi detergen ramah lingkungan. Dalam pembuatannya, biosurfaktan balik angin diaplikasikan dalam formulasi detergen laundry sebagai pengganti bahan sintetis (LAS) dan efektivitasnya dalam menghilangkan noda.

\section{METODE PELAKSANAAN KEGIATAN}

\section{Waktu, Tempat, dan Partisipan Kegiatan}

Kegiatan pengabdian dilaksanakan pada bulan September-Oktober 2020 di Desa Kampung Baru, Desa Mandi Angin Barat, Kecamatan Karang Intan, Kabupaten Banjar, Provinsi Kalimantan Selatan. Peserta kegiatan adalah kelompok ibu-ibu Yasinan Kampung Baru, namun adanaya pandemi Covid-19 maka penyuluhan dan pelatihan akan dilakukan pada 13 orang perwakilan anggota kelompok ibu-ibu yasinan.

\section{Bahan dan Alat}

Bahan yang digunakan adalah daun balik angin, minyak zaitun, minyak kelapa, minyak sawit, $\mathrm{NaOH}, \mathrm{NaCL}, \mathrm{STPP}$, metil etil sulfonat (MES), pengharum, soda abu, backing soda. Alat yang digunakan adalah alat-alat gelas, mixer, dan blender.

\section{Tahap Persiapan}

Pada tahap persiapan, kegiatan meliputi formulasi rencana dan penyusunan materi yang 
meliputi modul pelatihan yang meliputi bahan pembuatan sabun dan detergen, leaflet cara pembuatan sabun dan detergen serta kuesioner sebagai umpan balik dari pelatihan. Peralatan juga dipersiapkan untuk mendukung pelatihan yang akan dilaksanakan, seperti mikser untuk menghomogenkan bahan dan blender untuk mengecilkan ukuran daun balik angin.

\section{Tahap penyuluhan}

Pada tahap ini dijelaskan materi tentang tumbuhan balik angin dan manfaat tumbuhan balik angin. Pemberian informasi/penyuluhan dilakukan dengan cara ceramah kemudian dilanjutkan tanya jawab. Media yang digunakan pada pemberian informasi ini adalah laptop dan LCD. Media ini digunakan untuk memperlancar jalannya penyampaian informasi yang akan diberikan kepada kelompok ibu-ibu Yasinan Kampung Baru. Pemberian penyuluhan disertai dengan memberikan pendampingan. Diskusi yang dilakukan adalah terkait dengan bahaya penggunaan detergen kimia pada kesehatan dan lingkungan sekitar.

\section{Tahap pelatihan}

Pelatihan pengolahan daun balik angin menjadi sabun dan detergen diawali dengan memperkenalkan bahan dan alat yang digunakan untuk pembuatan sabun dan detergen, kemudian menjelaskan ukuran atau takaran bahan yang sesuai untuk menjadi suatu produk sabun dan detergen serta melakukan menjadi satu produk sabun dan detergen serta melakukan pelatihan bagaimana cara membuat sabun dan detergen dari daun balik angin secara tepat dan benar. Secara umum pelatihan dilakukan dalam tiga tahap, yaitu a) Penyiapan bahan baku yang meliputi: pencucian, penirisan, dan pemotongan; b) Pemaparan prinsip kerja dan teknis pembuatan detergen ramah lingkungan; dan c) Pelaksanaan pelatihan pembuatan detergen dari daun balik angin yang terdiri dari detergen cair dan detergen serbuk.

\section{Tahap Evaluasi}

Evaluasi bertujuan untuk menilai tingkat manfaat yang dapat dirasakan oleh peserta dan mengevaluasi kendala-kendala yang di hadapi oleh peserta selama kegiatan pelaksanaan program berlangsung, sehingga dapat mengetahui kendala dan solusi yang dilakukan untuk menyelesaikannya. Pengumpulan data dilakukan dengan membagikan kuisoner berupa pertanyaan-pertanyaan terkait pengetahuan peserta tentang detergen sebelum maupun setelah kegiatan. Hasil kuesioner tersebut kemudian diolah dalam bentuk persentase untuk mengetahui apakah terjadi peningkatan pengetahuan setelah dilakukannya kegiatan ini kemudian data tersebut dianalisis secara deskriptif.

\section{HASIL DAN PEMBAHASAN}

\section{Kegiatan Penyuluhun}

Persiapan kegiatan penyuluhan dimulai dengan mempersiapkan materi mengenai dampak penggunaan detergen kimia bagi kesehatan dan lingkungan. Tim pelaksana juga melakukan pembekalan kepada mahasiswa untuk mempermudah pelaksanaan kegiatan penyuluhan. Peserta sangat antusias mengikuti kegiatan penyuluhan ini. Peserta diberikan kusioner untuk menilai pemahaman terhadap materi penyuluhan yang diberikan. Selain kuisioer materi penyuluhan, peserta juga diberikan kuesioner kepuasan tentang kegiatan penyuluhan sebagai evaluasi bagi tim pelaksana terhadap kegiatan yang dilaksanakan. Kegiatan awal penyuluhan dilaksanakan pada 20 September 2020 dan dihadiri oleh 13 orang anggota kelompok ibu-ibu Yasinan Kampung Baru, Desa Mandi Angin. Pada pertemuan pertama ada empat sesi yang disampaikan, yaitu sesi pertama penyebaran kuesioner perihal pengetahuan warga tentang bahan kimia rumah tangga, yaitu detergen dan bahaya dampak penggunaan detergen kimia. Sesi kedua adalah penyuluhan tentang detergen ramah lingkungan yang berasal dari tumbuhan meliputi pemberian pengetahuan tentang bahaya detergen kimia, sumber bahan detergen yang ramah lingkungan yang bisa dibuat dari bahan nabati, pemberian informasi tentang bahan serta alat yang diperlukan untuk pembuatan detergen serta pemberian informasi tentang teknik dan prinsip dasar pembuatan detergen berbahan dasar tumbuhan.

Secara umum materi pada sesi kedua yang diberikan adalah mengenai detergen. Detergen adalah bahan yang membantu menghilangkan kotoran atau benda asing lainnya dari permukaan yang terkontaminasi (Yahaya et al. 2011). Detergen memiliki kemampuan untuk menghilangkan kotoran dari permukaan berpori (seperti kain dan pakaian) dan permukaan yang tidak berpori (seperti logam dan plastik). 
Sehingga, detergen banyak digunakan pada industri maupun rumah tangga (Ehilen et al. 2017). Detergen tersusun atas tiga komponen utama, yaitu surfaktan sebagai bahan dasar detergen yang berkisar antara 22-30\%, bahan builders (senyawa fosfat) serta bahan aditif (pemutih dan pewangi). Surfaktan merupakan molekul yang memiliki gugus polar yang suka air (hidrofilik) dan gugus non polar yang suka minyak (lipofilik) sekaligus, sehingga dapat mempersatukan campuran yang terdiri dari minyak dan air. Surfaktan pada umumnya disintesis dari turunan minyak bumi dan limbahnya dapat mencemarkan lingkungan, karena sifatnya yang sukar terdegradasi (Purnamasari 2014).

Efek yang dapat ditimbulkan oleh detergen di dalam air antara lain terbentuknya film akan menyebabkan menurunnya tingkat transfer ke dalam air, pada konsentrasi yang melebihi ambang batas yang ditentukan dapat menyebabkan gangguan kesehatan yang cukup serius, kombinasi antara polyphospat dengan surfaktan dalam detergen dapat mempertinggi kandungan phospat dalam air. Hal ini akan menyebabkan terjadinya eutrofikasi yang dapat menimbulkan warna pada air (Santi 2009). Eutrofikasi karena adanya senyawa fosfat dari detergen juga dapat menyebabkan tanaman perairan menjadi subur dan pertumbuhan alga menjadi meningkat melebihi batas normal atau biasa disebut dengan blooming (Suastuti et al. 2015).

Semakin meningkatnya pemakaian bahan detergen kimia oleh masyarakat atau industri, maka semakin meningkat pula potensi pencemaran yang diakibatkan oleh sisa pembuangan yang mengandung detergen kimia tersebut. Keberadaan detergen dalam air semakin meningkat dari ambang batas yang telah ditentukan sehingga akan mengakibatkan menurunnya kualitas air, yang pada akhirnya akan berakibat pada kualitas kesehatan masyarakat (Santi 2009). Balik angin merupakan tumbuhan yang dapat dijadikan sebagai alternatif detergen ramah lingkungan karena mengandung saponin yang dapat digunakan sebagai surfaktan alami. Penggunaan detergen ramah lingkungan dapat meminimalisir bahaya dampak detergen kimia pada lingkungan sehingga kesuburan tanah dapat terjaga. Gambar 1 menunjukkan kegiatan peyuluhan mengenai dampak penggunaan detergen kimia.

Surfaktan alami dapat diperoleh dari sumber tumbuhan atau hewan. Saponin merupakan kelas biosurfaktan nonionik yang berasal dari tumbuhan. Saponin sebagai surfakatan alami yang

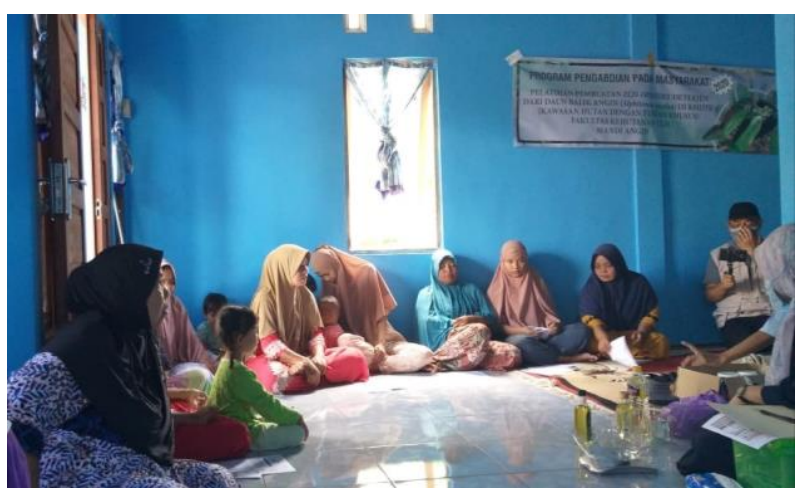

Gambar 1 Kegiatan peyuluhan mengenai dampak penggunaan detergen kimia.

dapat diaplikasikan pada industri makanan, kosmetik seperti detergen, peningkatan kelarutan, dan pengurangan tegangan antar muka (Tmáková et al. 2016). Penggunaan saponin sebagai sabun cuci belum membuktikan efek beracun pada kulit atau mata manusia. Surfaktan alami memiliki beberapa keunggulan dibandingkan yang disintesis secara kimia, dan memiliki risiko lingkungan yang rendah karena asal-usul alaminya (Song et al. 2008). Beberapa keuntungan dari senyawa tersebut dibandingkan yang sintetis adalah biodegradabilitas, toksisitas rendah, biokompatibilitas, biaya rendah dan spesifisitas, tersedia dalam jumlah besar serta sangat efektif dalam kondisi ekstrim seperti suhu dan pH (Tmáková et al. 2016).

Sesi ketiga dari kegiatan adalah penyebaran kuesioner perihal pengetahuan warga tentang detergen yang secara garis besar meliputi hal-hal berikut: a) Pengetahuan umum peserta tentang detergen dan jenis-jenis detergen; b) Pengetahuan peserta tentang fungsi detergen; c) Pengetahuan peserta tentang dampak detergen; dan d) Pengetahuan peserta tentang bahan baku dan cara pembuatan detergen. Data hasil kuesioner kemudian dianalisa untuk mengetahui sejauh mana bertambahnya pengetahuan warga tentang pengetahuan bahaya dampak detergen kimia. Data hasil kuisoner awal dan akhir dapat dilihat pada Tabel 1.

Berdasarkan hasil kuisoner pada Tabel 1 menunjukkan sebelum kegiatan penyuluhan secara keseluruhan warga desa Kampung Baru Mandi Angin belum pernah mendapatkan penyuluhan yang serupa dan belum banyak mengetahui dampak detergen bagi lingkungan. Selain itu, peserta juga belum mengetahui mengenai detergen ramah lingkungan yang terbuat dari tumbuhan, namun setelah kegiatan secara keseluruhan menyatakan bahwa mereka menjadi paham dan mengerti. Hasil kegiatan 
Tabel 1 Hasil jawaban kuesioner awal dan akhir kegiatan penyuluhan

\begin{tabular}{|c|c|c|c|c|}
\hline \multirow{3}{*}{ Pertanyaan } & \multicolumn{4}{|c|}{ Jumlah jawaban (\%) } \\
\hline & \multicolumn{2}{|c|}{ Sebelum kegiatan } & \multicolumn{2}{|c|}{ Setelah kegiatan } \\
\hline & Ya & Tidak & Ya & Tidak \\
\hline Apakah anda menggunakan produk pembersih sehari-hari & 90 & 10 & 90 & 10 \\
\hline Apakah anda mengetahui jenis jenis produk pembersih & 50 & 50 & 95 & 5 \\
\hline Apakah anda menggunakan detergen & 90 & 10 & 90 & 10 \\
\hline Apakah anda mengetahui bahan-bahan komponen detergen & 0 & 10 & 90 & 10 \\
\hline Apakah anda mengetahui bahan dasar untuk pembuatan detergen & 0 & 100 & 90 & 10 \\
\hline Apakah anda mengetahui jenis-jenis detergen & 0 & 100 & 90 & 10 \\
\hline Apakah anda mengetahui manfaat detergen & 70 & 30 & 90 & 10 \\
\hline $\begin{array}{l}\text { Apakah anda mengetahui dampak penggunaan detergen sintetis } \\
\text { bagi kesehatan }\end{array}$ & 17 & 83 & 70 & 30 \\
\hline $\begin{array}{l}\text { Apakah anda mengetahui dampak penggunaan detergen sintetis } \\
\text { bagi lingkungan }\end{array}$ & 30 & 70 & 80 & 20 \\
\hline Apakah anda mengetahui tentang detergen ramah lingkungan & 20 & 80 & 75 & 25 \\
\hline Apakah anda menggunakan detergen ramah lingkungan & 0 & 100 & 40 & 60 \\
\hline Apakah anda mengetahui produk detergen ramah lingkungan & 20 & 80 & 40 & 60 \\
\hline $\begin{array}{l}\text { Apakah anda mengetahui daun tumbuhan Balik Angin bisa } \\
\text { digunakan sebagai bahan pada pembuatan detergen }\end{array}$ & 0 & 100 & 80 & 20 \\
\hline $\begin{array}{l}\text { Apakah anda pernah mendapatkan penyuluhan tentang pembuatan } \\
\text { detergen }\end{array}$ & 0 & 100 & 100 & 0 \\
\hline $\begin{array}{l}\text { Apakah anda mendapatkan manfaat dari penyuluhan tentang } \\
\text { pembuatan detergen }\end{array}$ & 0 & 100 & 90 & 10 \\
\hline
\end{tabular}

penyuluhan ini juga menjadikan warga mengetahui bahwa daun balik angin bisa digunakan sebagai bahan dasar untuk pembuatan detergen ramah lingkungan. Beberapa faktor ini menjadikan kegiatan penyuluhan pada pertemuan pertama ini diikuti oleh warga dengan sangat antusias. Antusias warga terlihat dari banyaknya pertanyaan yang diajukan terkait penggunaan detergen. Semua pertanyaan-pertanyaan tersebut dijawab dengan baik oleh tim pelaksana dan masyarakat puas dengan jawaban yang diberikan. Kegiatan penyuluhan meningkatkan pengetahuan peserta sekitar $\pm 90 \%$ wawasan masyarakat terhadap penggunaan detergen, yaitu 11 dari 13 peserta kegiatan dapat memahami materi yang diberikan terkait dengan bahaya detergen sintetis.

Kendala yang dihadapi saat memberikan penyuluhan adalah karena sebagian kecil dari partisipan adalah ibu-ibu dengan umur di atas 60 tahun, sehingga sulit untuk menerima materi yang diberikan. Namun, materi yang diberikan masih dapat dimengerti oleh partisipan lainnya sehingga kerberhasilan penyuluhan akan dampak detergen dapat meningkatkan wawasan dan pengetahuan masyarakat.

Setelah tahap penyuluhan dilaksanakan, kegiatan selanjutnya adalah pelatihan pembuatan detergen daun balik angin. Dari pelatihan tersebut dilaksanakan evaluasi melalui kuesioner yang diisi oleh masing-masing peserta pelatihan.
Kuesioner ini bertujuan untuk melihat efektivitas dari kegiatan pelatihan terhadap peran serta peserta untuk dapat membuat sendiri detergen dari daun balik angin. Berdasarkan data hasil evaluasi pelatihan pada Tabel 2, dapat disimpulkan bahwa para peserta pelatihan dapat memahami dan mempraktikkan pembuatan detergen alami dari daun balik angin. Sekitar $77,75 \%$ atau 10 dari 13 orang peserta kegiatan dapat memahami cara membuat detergen ramah lingkungan dari daun balik angin.

\section{Pengolahan Ekstrak Daun Balik Angin}

Daun angin yang dipilih adalah daun balik angin yang sudah tua karena kadar saponin pada daun balik angin yang tua lebih tinggi dibandingkan dengan daun balik angin yang muda agar menjaga keberlangsungan pertumbuhan pada pohon balik angin. Pada pengujian saponin pada daun balik angin, diperoleh hasil positif bahwa daun balik angin mengandung saponin, ini dikarenakan pada saat penambahan menggunakan air, daun balik angin mengaluarkan buih yang bertahan selama kurang lebih 10 menit yang menandakan bahwa buih tersebut adalah saponin.

Saponin merupakan suatu glikosida yang memiliki aglikon berupa sapogenin. Saponin dapat menurunkan tegangan permukaan air, sehingga akan mengakibatkan terbentuknya buih 
Tabel 2 Hasil evaluasi kegiatan pelatihan pembuatan detergen

\begin{tabular}{lrr}
\hline \multicolumn{1}{c}{ Pertanyaan } & \multicolumn{2}{c}{ Jumlah jawaban (\%) } \\
& \multicolumn{1}{c}{ Ya } & \multicolumn{1}{c}{ Tidak } \\
\hline $\begin{array}{l}\text { Apakah anda pernah sebelum kegiatan praktik pembuatan detergen saat ini, } \\
\text { melakukan praktik sendiri }\end{array}$ & 66 & 34 \\
Apakah anda mengetahui cara dan tahapan dalam pembuatan detergen & 80 & 20 \\
Apakah anda bisa membuat sendiri detergen & 70 & 30 \\
Apakah anda berkeinginan untuk membuat detergen sendiri & 75 & 25 \\
Jika anda sudah bisa membuat sendiri detergen dan apakah ada keinginan untuk & 66 & 34 \\
menjualnya sebagai pendapatan tambahan keluarga & 75 & 25 \\
Apakah anda berkeinginan untuk berwirausaha memproduksi detergen & 100 & 0 \\
Apakah praktik membuat detergen secara mandiri pada kegiatan ini bermanfaat & 10 \\
untuk anda & 90 & 10 \\
\hline
\end{tabular}

pada permukaan air setelah dikocok. Sifat ini mempunyai kesamaan dengan surfaktan yang digunakan pada detergen. Penurunan tegangan permukaan disebabkan karena adanya senyawa sabun yang dapat merusak ikatan hidrogen pada air. Senyawa sabun ini memiliki dua bagian yang tidak sama sifat kepolarannya. Struktur kimia saponin merupakan glikosida yang tersusun atas glikondan aglikon. Bagian glikon terdiri dari gugus gula seperti glukosa, fruktosa, dan jenis gula lainnya. Bagian aglikon merupakan sapogenin. Sifat ampifilik ini dapat membuat bahan alam yang mengandung saponin bisa berfungsi sebagai surfaktan (Nurzaman et al. 2018). Surfaktan diperlukan pada pembuatan detergen agar mengurangi tegangan permukaan antara air dan permukaan kain yang terkena noda seperti minyak atau lumpur sehingga akan mempermudah terjadi pembasahan. Semakin kecil tegangan antara air dan permukaan kain, maka akan semakin besar daya detergensinya untuk membersihkan noda pada kain tesebut.

Tahapan pembuatan ekstrak daun balik angin adalah pertama mencuci daun balik angin dengan air mengalir, kemudian dipotong-potong sangat kecil, dan dikeringkan dengan cara dianginanginkan tanpa terkena sinar matahari langsung. Daun balik angin yang telah kering kemudian dihaluskan dengan blender untuk mendapatkan ukuran daun balik angin yang lebih kecil. Ekstrak daun balik angin diperoleh dengan metode pemanasan. Daun balik angin dipanaskan dengan menggunakan air hingga mendidih pada suhu $70-75^{\circ} \mathrm{C}$ selama kurang lebih 15 menit, kemudian hasil ekstrak cair yang diperoleh disaring dan disimpan dalam wadah untuk digunakan selanjutnya. Gambar 2 menunjukkan proses pembuatan ekstrak daun balik angin. Salah satu cara untuk mengawetkan ekstrak daun balik angin adalah dengan menambahkan etanol sebanyak 8\% untuk mencegah tumbuhnya jamur dan kapang yang dapat menganggu kualitas dari ekstrak. Ekstrak yang dihasilkan adalah berupa ekstrak air, yang dapat menjadi media pertumbuhan bagi kapang dan jamur.

\section{Pembuatan Detergen Daun Balik Angin}

Detergen berhubungan dengan pembersihan benda padat, menghilangkan benda yang tidak diinginkan dari permukaan. Proses pembersihan ini dapat dilakukan dengan berbagai cara, termasuk pemisahan mekanis sederhana (misalnya menggosok dan mencelupkan kain ke dalam air), memisahkan dengan pelarut (misalnya penambahan pelarut organik), dan pemisahan dengan menambahkan air dan bahan kimia seperti surfaktan. Sistem pencucian dengan detergen terdiri dari benda-benda yang akan dibersihkan yaitu substrat, kotoran, dan noda yang akan dibersihkan melalui proses pencucian. Hasil pencucian akan bergantung pada interaksi elemen dan kondisi pencucian yang digunakan, seperti suhu, waktu, energi mekanik yang diberikan, dan kesadahan air yang digunakan. Detergen memiliki formula untuk membersihkan substrat yang kotor dalam berbagai kondisi pencucian. Beberapa detergen, seperti sabun mandi, hanya terdiri dari satu komponen. Beberapa detergen lain memiliki lebih dari satu komponen. Formula detergen pada umumnya mengandung lebih dari satu bahan yang terdiri dari surfaktan, builder, filler, dan aditif. Bahan pelengkap seperti pelembut air/zat pengkelat, zat anti redeposisi, enzim, zat pemutih, zat pendispersi, parfum, dan zat tambahan kecil lainnya juga termasuk dalam formulasi komersial (Helmy et al. 2020). 


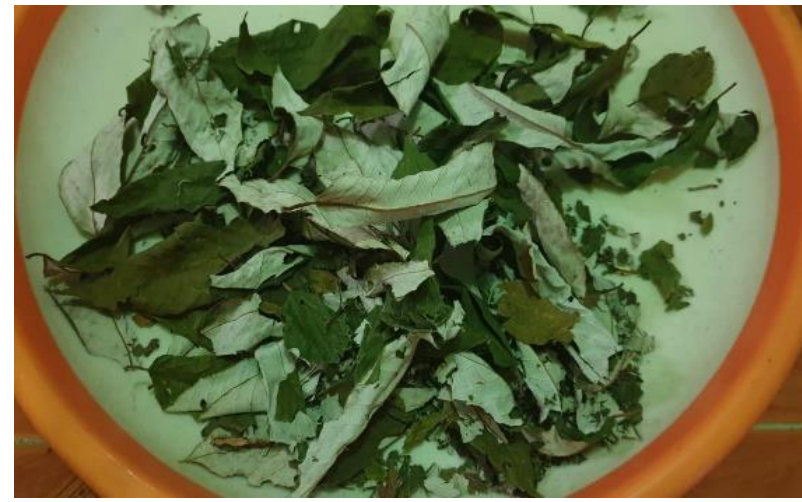

a

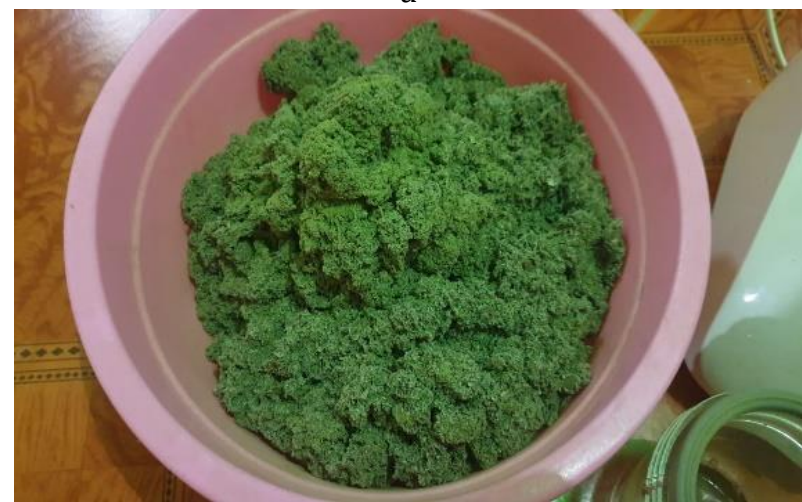

C

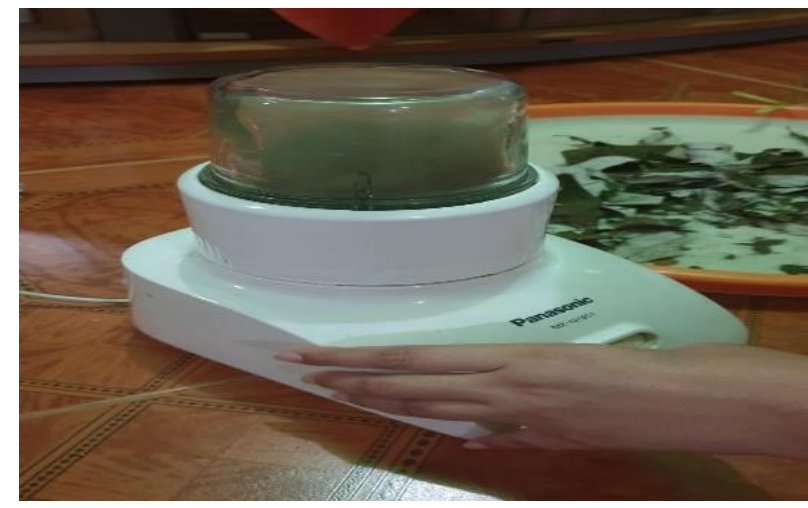

b

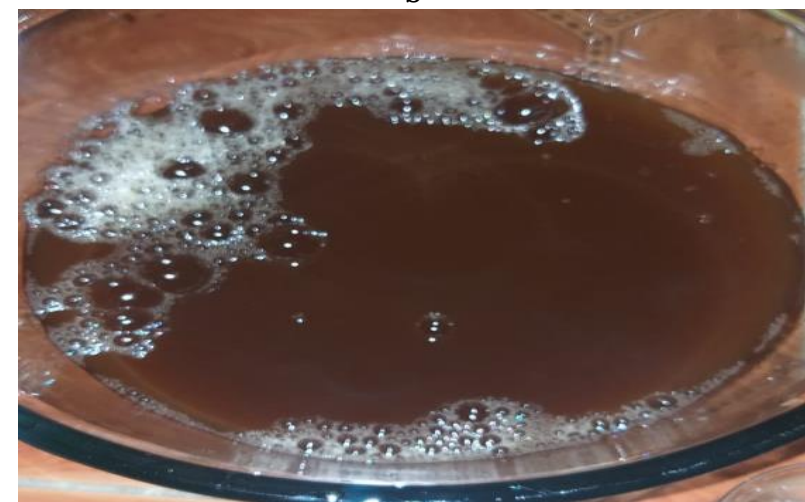

d

Gambar 2 Proses pembuatan ekstrak daun balik angin: a) Daun balik angin yang telah diangin-angin; b) Penghaluasa daun balik angin dengan blender; c) Daun balik angin yang telah halus; dan d) Ekstrak daun balik angin.

Detergen daun balik angin dibuat dalam dua bentuk, yaitu detergen cair dan bubuk. Detergen memiliki bentuk bermacam-macam, di antaranya adalah detergen bubuk dan cair. Detergen cair biasanya banyak digunakan untuk usaha laundry karena efektivitasnya dalam penggunaan skala besar. Sedangkan detergen bubuk biasanya digunakan oleh ibu rumah tangga. Pada kegiatan ini pembuatan detergen dibuat dari bahan-bahan yang mudah diperoleh dan aman digunakan. Pemilihan kedua bentuk detergen dalam kegiatan ini adalah agar peserta dapat mengetahui lebih detail perbedaan detergen cair dan bubuk, karena pada kehidupan sehari-hari kedua detergen ini banyak digunakan dan mudah diperoleh. Kegiatan pembuatan detergen daun balik angin ditunjukkan pada Gambar 3 dan detergen yang dihasilkan terlihat pada Gambar 4.

Pada pembuatan detergen bubuk, dibutuhkan bahan-bahan berupa soda abu dan backing soda. Fungsi dari backing soda pada pembuatan detergen adalah untuk menghilangkan bau tak sedap pada pakaian dan membantu agar warna pada pakaian tidak memudar serta dapat melembutkan pakaian. Sedangkan fungsi soda abu adalah untuk membersihkan noda yang menempel pada pakaian. Proses pembuatan detergen

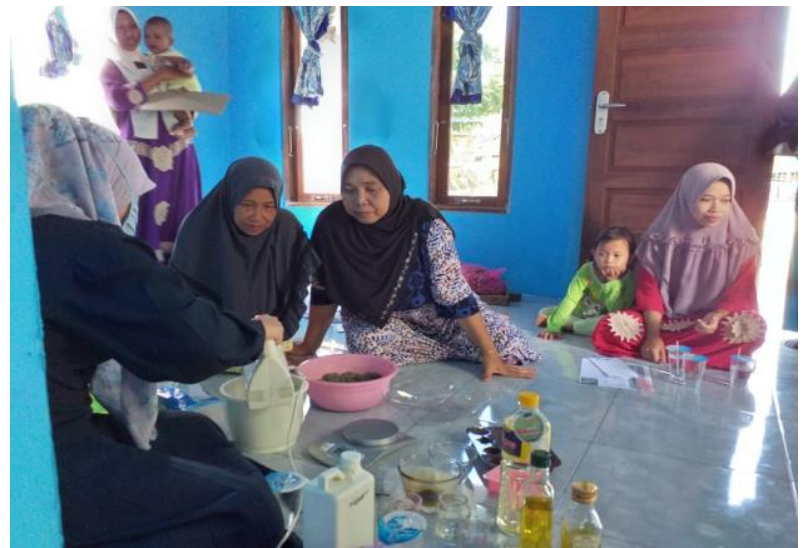

Gambar 3 Kegiatan pembuatan detergen bubuk dan cair.

bubuk membutuhkan waktu yang sedikit lebih panjang dibandingkan pada pembuatan detergen cair, karena dalam proses pembuatannya akan sulit dilakukan jika bahan aktif yang digunakan adalah berupa infusa daun balik angin. Karakteristik infusa balik angin berupa ekstrak cair, jika digunakan dalam pembuatan detergen bubuk maka detergen bubuk yang diperoleh akan bersifat higroskopis dan menganggu penampilan detergen yang dihasilkan. Sabun daun balik angin perlu dibuat terlebih dahulu untuk mengatasi hal tersebut. Sabun daun balik angin dibuat dengan 
metode cold process menggunakan minyak zaitun, minyak sawit, minyak kelapa, dan $\mathrm{NaoH}$, kemudian sabun yang telah melalui proses curing selama 24 jam dapat digunakan. Sabun daun balik angin kemudian diserut dan dicampurkan dengan bahan-bahan lain pada pembuatan detergen bubuk. Formula dan prosedur pembuatan detergen bubuk dan cair dari daun balik angin terlihat pada Tabel 3.
Dampak kegiatan ini bagi masyarakat adalah masyarakat dapat menggunakan detergen ramah lingkungan dari daun balik angin dibandingkan dengan detergen kimia karena akan lebih ekologis dan ekonomis. Limbah daun balik angin dapat diuraikan oleh alam dan tingkat pencemarannya hampir tidak ada. Air bekas mencuci bisa digunakan untuk menyiram tanaman. Jadi, mencuci menggunakan daun balik angin dapat

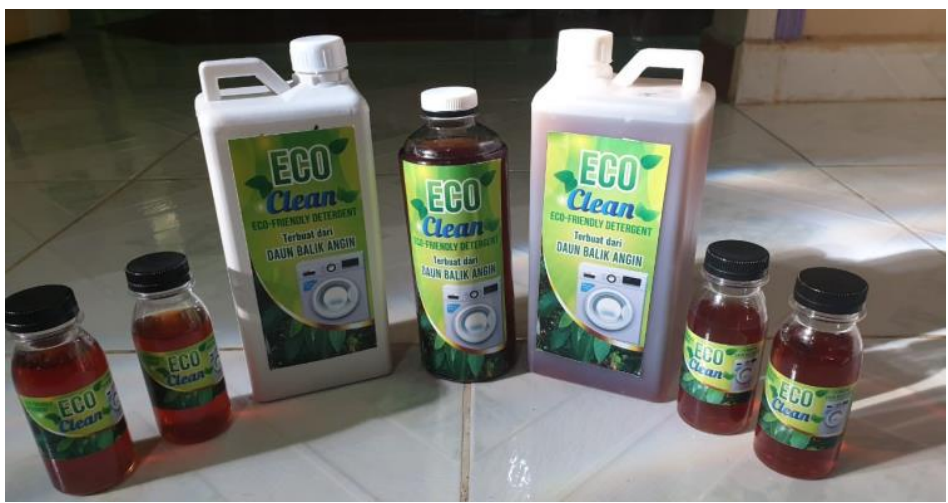

a

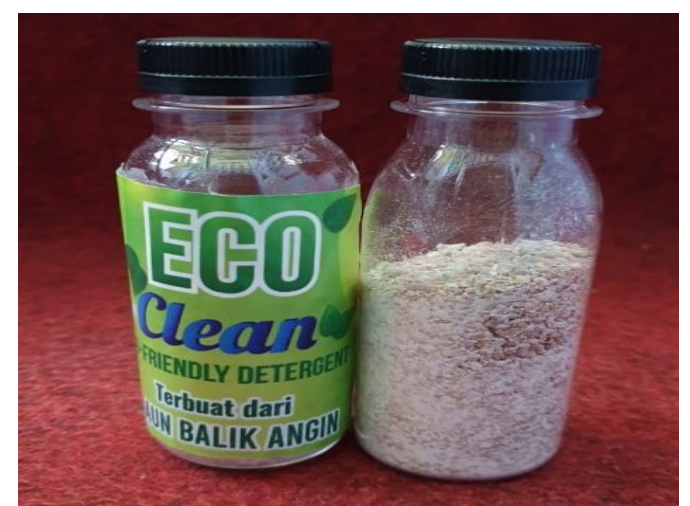

b

Gambar 4 Detergen yang dihasilkan dari daun balik angin: a) Detergen cair dan b) Detergen bubuk.

Tabel 3 Formula dan prosedur pembuatan sabun batang, detergen bubuk, dan cair dari daun balik angin

\begin{tabular}{|c|c|c|}
\hline Bahan & Takaran & Prosedur pembuatan \\
\hline \multicolumn{3}{|l|}{ Sabun batang } \\
\hline Ekstrak daun balik angin & $100 \mathrm{~mL}$ & $\begin{array}{l}\text { Timbang masing-masing komponen minyak sesuai dengan } \\
\text { takaran }\end{array}$ \\
\hline Minyak zaitun & $97 \mathrm{~g}$ & Timbang $\mathrm{NaOH}$, masukkan ke dalam ekstrak daun balik angin \\
\hline Minyak kelapa & $52 \mathrm{~g}$ & Campurkan minyak dan larutan ekstrak balik angin, kemudian \\
\hline Minyak sawit & $59 \mathrm{~g}$ & mikser sampai mengental \\
\hline $\mathrm{NaoH}$ & $41 \mathrm{~g}$ & Tambahkan pengharum secukupnya \\
\hline Pengharum & secukupnya & Tuang kedalam cetakan, diamkan 24 jam \\
\hline \multicolumn{3}{|l|}{ Detergen bubuk } \\
\hline Sabun batang balik angin & $1 \mathrm{Bar}$ & Parut sabun balik angin, kemudian blender \\
\hline Soda Abu & 2 cup & Campurkan dengan soda abu dan backing soda, tambahkan \\
\hline Backing Soda & 2 cup & pengharum kemudian aduk hingga rata \\
\hline Pengharum & secukupnya & Simpan di dalam wadah tertutup \\
\hline \multicolumn{3}{|c|}{ Detergen cair (bahan untuk $500 \mathrm{~mL}$ ) } \\
\hline Ekstrak balik angin & $15 \mathrm{~g}$ & Timbang masing-masing bahan \\
\hline MES (Metil Eter Sulfonat) & $15 \mathrm{~g}$ & Larutkan MES dengan air panas hingga larut (A) \\
\hline Natrium Karbonat & $10 \mathrm{~g}$ & Larutkan $\mathrm{NaCl}$ dengan sedikit air (B) \\
\hline STPP & $10 \mathrm{~g}$ & $\begin{array}{l}\text { Masukan larutan B ke dalam larutan A, aduk hingga mengental } \\
\text { kemudian tambahkan air sedikit demi sedikit }\end{array}$ \\
\hline $\mathrm{NaCl}$ & $2 \mathrm{~g}$ & Masukan ekstrak balik angin sambil sesekali diaduk \\
\hline Pengharum & secukupnya & $\begin{array}{l}\text { Masukan STPP aduk hingga melarut sambil ditambahkan air } \\
\text { sedikit demi sedikit }\end{array}$ \\
\hline Air & $500 \mathrm{~mL}$ & $\begin{array}{l}\text { Masukan Na karbonat ke dalam campuran di atas, aduk hingga } \\
\text { merata sambil ditambahkan air sedikit demi sedikit hingga } \\
\text { volume } 500 \mathrm{~mL} \\
\text { Tambahkan pengharum secukupnya dansimpan dalam wadah } \\
\text { tertutup }\end{array}$ \\
\hline
\end{tabular}


mengurangi pemborosan penggunaan air dan mengurangi dampak penggunaan detergen kimia pada lingkungan. Kendala yang dihadapi pada kegiatan pengabdian ini adalah masyarakat masih merasa asing dengan bahan-bahan tambahan dalam pembuatan detergen dan kesulitan untuk membeli bahan tersebut karena mereka jarang menggunakan aplikasi e-commerce dalam kehidupan sehari-hari, sehingga untuk mengatasi hal tersebut perlu diadakan pelatihan penggunaan social media dan e-commerce sebagai upaya keberlanjutan kegiatan pengabdian. Selain itu, dilakukan pendampingan untuk memasarkan produk detergen daun balik angin. Kegiatan pengabdian ini adalah salah satu upaya untuk memanfaatkan sumber daya alam dan keahlian yang dimiliki oleh masyarakat dalam membuat detergen menjadi sumber ekonomi bagi masyarakat sekitar kawasan KHDTK. UMKM adalah wadah yang tepat untuk menyalurkan produk detergen balik angin hasil olahan masyarakat sekitar.

\section{SIMPULAN}

Kegiatan pengabdian masyarakat ini secara keseluruhan berjalan dengan baik, animo peserta pelatihan sangat tinggi, serta pengetahuan masyarakat meningkat akan dampak penggunaan detergen kimia. Berdasarkan hasil posttest yang diperoleh terkait pengetahuan warga tentang detergen, terdapat peningkatan pengetahuan dan wawasan terkait jenis, dampak, dan komponen detergen. Peserta juga memahami pembuatan detergen sendiri yang lebih ramah lingkungan menggunakan daun balik angin, sehingga keterampilan dalam membuat detergen meningkat. Detergen yang dibuat adalah berupa detergen bubuk dan detergen cair. Saran untuk kegiatan ini adalah perlu peninjauan lebih lanjut untuk dapat membentuk UMKM bagi ibu-ibu Desa Mandi Angin untuk mengelola dan memproduksi detergen dari daun balik angin sehingga dapat dijadikan sebagai sumber ekonomi bagi masyarakat sekitar kawasan KHDTK.

\section{UCAPAN TERIMA KASIH}

Ucapan terima kasih disampaikan kepada Dekan Fakultas Kehutanan Universitas Lambung Mangkurat yang telah mendanai kegiatan ini melalui Skema Program Kemitraan Masyarakat tahun 2020.

\section{DAFTAR PUSTAKA}

Ehilen OE, Obadoni BO, Imade FN, Eseigbe D, Mensah JK. 2017. The effect of detergents on the germination and growth of Amaranthus hybridus L. and Solanum lycopersicon $L$. Nigerian Annals of Natural Sciences. 16(1): 100-108.

Haderiah H, Dewi NU. 2016. Meminimalisir kadar detergen dengan penambahan koagulan dan filtrasi media saring pada limbah kamar mandi. HIGIENE: Jurnal Kesehatan Lingkungan. 1(1): 33-41.

Helmy Q, Gustiani S, Mustikawati AT. 2020. Application of rhamnolipid biosurfactant for bio-detergent formulation. In: IOP Conference Series: Materials Science and Engineering. 823(1): 012-014. https://doi.org/10.1088/ 1757-899X/823/1/012014

Hendra H, Barlian, Razak A, Sanjaya H. 2016. Photo-degradation of surfactant compounds using UV rays with addition of $\mathrm{tio}_{2}$ catalysts in laundry waste. Sainstek: Jurnal Sains dan Teknologi. 7(1): 59-68. https://doi.org/10. 31958/js.v7i1.126

Nurzaman F, Djajadisastra J, Elya B. 2018. Identifikasi kandungan saponin dalam ekstrak kamboja merah (Plumeria rubra L.) dan daya surfaktan dalam sediaan kosmetik. Jurnal Kefarmasian Indonesia. 8(2): 85-93. https://doi. org/10.22435/jki.v8i2.325

Purnamasari EN. 2014. Karakteristik kandungan linear alkyl benzene sulfonat (LAS) pada limbah cair laundry. Jurnal Media Teknik. 11(1): 32-36.

Rachmawati PA. 2019. Biodegradable Detergen Dari Saponin Daun Waru Dan Ekstraksi Bunga Tanjung. Indonesian Chemistry and Application Journal. 2(2): 1-4. https://doi.org/10.26740/ icaj.v2n2.p1-4

Santi SS. 2009. Penurunan konsentrasi surfactan pada limbah detergen dengan proses photokatalitik sinar UV. Jurnal Teknik Kimia. 4(1): 260-264.

Suastuti DA, Suarsa IW, Putra DK. 2015. Pengolahan larutan detergen dengan biofilter tanaman kangkung (ipomoea crassicaulis) 
dalam sistem batch (curah) teraerasi. Jurnal Kimia FMIPA. 9(1): 98-104.

Supandi L, Setiawan DA. 2019. Pemanfaatan daun waru (Hibiscus tiliance $L$ ) sebagai bahan baku detergen. Sainteks: Jurnal Sains dan Teknik. 1(1): 17-28. https://doi.org/10.37577/ sainteks.v1i1.107

Song SS, Zhu LZ, Zhou WJ. 2008. Simultaneous removal of phenanthrene and cadmium from contaminated soils by saponin, a plantderived biosurfactants. Environmental Pollution. 156: 1368-1370. https://doi.org/ 10.1016/j.envpol.2008.06.018

Tmáková L, Sekretár S, Schmidt Š. 2016. Plantderived surfactants as an alternative to synthetic surfactants: surface and antioxidant activities. Chemical Papers. 70(2): 188-196. https://doi.org/10.1515/chempap-20150200

Wisetkomolmat J, Suppakittpaisarn P, Sommano S. 2019. Detergent plants of northern thailand: potential sources of natural saponins. Resources. 8(1): 1-14. https://doi.org/ $10.3390 /$ resources 8010010

Yahaya T, Okpuzor J, Oladele EO. 2011. Investigation of toxicity of detergents. Journal of Environmental Science and Technology. 4(6): 638-645. https://doi.org/10.3923/ jest.2011.638.645 